Original Research Paper

\title{
Effect of Parameters of Selection and Replacement Drilling Bits Based on Geo-Mechanical Factors: (Case Study: Gas and Oil Reservoir in the Southwest of Iran)
}

\author{
Arzhang Nabilou \\ Center of Natural Resources and Environment (CERENA), \\ Instituto Superior Técnico, Technical University of Lisbon, Av. Rovisco Pais, 1049-001, Lisbon, Portugal
}

Article history
Received: 07-04-2016
Revised: 02-05-2016
Accepted: 09-05-2016

Email: arzhang143@gmail.com

\begin{abstract}
The purpose of the present study was to explore the effect of drill bit selection parameters on enhanced oil and gas recovery fin Iranian oil and gas fields. In this study, many methods and parameters were discussed. These parameters are practically tested on many wells in southwestern field of Iran. Out of common drill bit selection methods, length unit drilling cost is the most popular one owing to the direct investigation of economic parameters related to the performance of the drill bit. However, previous studies conducted in one of the southern gas fields of Iran showed that this method's results do not yield the optimal drill selection and geology since it fails to evaluate drill bits used in various drilling conditions. To address this problem, some methods have been introduced as complementary of this method which allow comparing various drill bits. In the present work, it was illustrated that using geo-mechanical factors are ideal complements for the method of length unit drilling cost in Iran.
\end{abstract}

Keywords: Drill Bit Selection, Geo-Mechanical Factors, Drilling Resistance Method, Southwest of Iran

\section{Introduction}

Drill bit is the main tool used by drilling engineer and the best drill bit selection and its corresponding drilling conditions is one of the most essential problems that drillers face with. Previously, before producing drill bits with new and innovative designs and the improvement of previous designs, selecting appropriate drill bit was a relatively simple process. Although, currently, the diversity of drill bits is very high and the process of drill bit selection process has become more complex, new methods have been introduced for the appropriate drill bit selection.

Appropriate drill bit selection for specific drilling conditions requires evaluating various contributing factors. Of course, if all factors which influence drill bit selection are studied, drill bit selection will become significantly complex. Hence, each of drill bit selection methods evaluates only a limited range of factors.

There are a lot of works investigating optimal drill bit selection. Jansen studied the vibrational behavior of drill stem as a rotor. He studied the effect of contact with the wall and its friction on the rotational behavior of the drill stem (Jansen, 1990; Jasen and Van Den Steen, 1993). He modeled mass and damping of fluid obtained from the experiments. In this study, he did not consider the effect of drilling mud on the vibrations of the drill stem. In his analysis, he investigated forward and backward movement of the drill stem and found the effect of various parameters on it.

In their study, Yigit and Christoforou (1996) investigated the effect of longitudinal and transverse vibrations of drill stem under the impact of axial force. In their work, from the drill stem, only the drill bit length was modeled and drill pipe was not included in modeling. They considered the effect of drilling mud as equivalent mass and damping and did not consider mud discharge on longitudinal and transverse vibrations.

In this study, drill stem has been considered as a beam which is excited through axial force imposed from the bottom of the well by means of the rotation of the drill stem. Moreover, the effect of contact with wall has been considered using Hertzian contact stress model in this study. They studied drill stem buckling under the 
impact of axial force. They also evaluated the buckling of drill stem for linear and nonlinear cases. In another work, Yigit and Christoforou (1997) investigated vibrations of a drill bit with rotation and they considered its torsional vibrations besides longitudinal and transverse vibrations. In fact, they completed their earlier work in this study. In this research, the effect of fluid has been modeled only by equivalent mass and damping and the effect of mud flow discharge on the drill stem vibrations was not modeled.

Khuleif and Al-Naser (2005) explored the longitudinal, transverse and torsional vibrations of drill stem as a rotor. They also studied the gyroscopic behavior of the drill stem. Of course, in their work, the effect of drilling mud and wall contact as well as friction were not taken into consideration and only the effect of neutral point on natural frequency of the drill stem and its time response in transverse direction was studied.

Regarding fluid-structure interaction, a great deal of researches has been carried out and each of them modeled this effect in a different manner. Out of papers published in this field, papers written by Paidoussis and Issid (1973; Paidoussis, 1966) are the best researches on the effect of drilling mud on drill stem vibrations. In this research, an analytical formulation for fluid-structure interaction within a pipe through which fluid flow passes has been proposed. Additionally, the analytical formula was also obtained for a cylinder which is placed in another cylinder and the space between the two cylinders is filled with fluid. In addition to being brief, these formulations include all of the effects of equal mass, damping and flexibility of the fluid and are sufficient for modeling drill stem vibrations with respect to user demands.

\section{Evaluation Parameters of the Research}

\section{Length Unit Drilling Cost Method}

Drilling cost of a drilled interval of a well, in the sum of the cost of drill bit price, drill bit replacement cost and driving, drilling rig operations cost for drilling time (Thomas, 1989). If the cost of driving drill is divided by drilled length, length unit drilling cost will be obtained. Length unit drilling cost of a certain drill bit will be minimized if the weight on the drill bit and the rotation speed are appropriately selected (Adams and Charrier, 1985; Bourgoyne et al., 1991).

Average time required for moving drilling string and replacing drill bit for different depths of well and various sizes of drill bit can be extracted from the available tables. In another common method, instead of using table, one can consider one hour for each $1000 \mathrm{ft}(305 \mathrm{~m})$ depth.

Until drilling cost function do not consider drilling risk factors, drilling cost's evaluation results must be modified by engineering judgement. If the risk of facing drilling problems such as pipe trapping, well deviation and etc. is considerably increased, drill bit driving cost reduction will not necessarily lead to the reduction of a well's cost.

\section{Method of Specific Energy}

Due to the problems of evaluating drill bit through length unit drilling cost method, it seems that a simple and practical method which can measure the performance of a drill bit in every drilling range (formation) will be a great assistance for drilling engineer. It is also possible that its results can be correlated with length unit drilling cost for drill bit selection (Rabia et al., 1986). Therefore, in this regard and as a complementary method which can enable optimal drill bit selection using drill bit, specific energy method is used.

For the first time, the concept of Specific Energy (SE) in rock drilling was introduced by Tile (Teale, 1965) as an index for measuring the mechanical efficiency of the works carried on rock. SE is defined as the energy required for drilling unit volume of rock. This term has been widely used previously conducted studies on rocks as an index for efficiency and a measure for drilling capability scale. For drilling a certain volume of rock, a minimum energy which can be theoretically calculated is required. This value depends on the nature and characteristics of rock. Practically, during this volume of rock, the value of energy will be higher or at least equal to the minimum estimated value.

The difference between theoretical and actual values as well as the difference between actual values when using various drilling tools represents the presence of some additional work. For example, re-drilling drilled rocks, overcoming friction and energy transferred to rocks surrounding well and heating up drilling fluid can be referred. In addition, the value of specific energy for different tools which drill the same rock can be employed as a scale for determining a tool with the highest efficiency under current drilling conditions.

Furthermore, SE can be used as an index to show lithological changes and modify drill bit based on drilling function. SE method is not merely used for drill bit selection but it can be used as a complementary tool from other methods such as investigating previous drill bits records and length unit drilling cost (Farrelly and Rabia, 1987).

In rotational drilling, work can be divided into two parts: The work done by axial force and work done by rotational component. Specific energy can be provided using Equation 27 (Rabia et al., 1986). Moreover, equation shows that for a specific drill bit in a formation with specific resistance, SE is constant for each combination of weight over the drill bit and rotation speed. It is because the increase in WN leads to the 
improvement of penetration rate under optimal hydraulic conditions, which maintains SE relation balance. Since penetration rate is strongly affected by WN changes and for a certain drill bit, abundant values are obtained for penetration rate in each of $\mathrm{WN}$ values. When $\mathrm{SE}$ is compared with penetration rate, its lower sensitivity to WN changes turns it into a suitable tool for drill bit selection. On the other hand, $\mathrm{SE}$ is a direct measure for drill bit application in a certain formation and provides an index for evaluating the mutual effect of drill bit and rock (Rabia, 1985).

If $\mathrm{SE}$ is appropriately used to evaluate the performance of drill bit, it can be considered as an appropriate tool for drill bit selection. Since optimal drilling is recognized with its low SE, drill bits which produce the least SE for a certain rock are considered as suitable drill bit for the next uses in the same formation in the same conditions (Farrelly and Rabia, 1987).

\section{Drilling Potential}

In large scales, drilling potential of formation predict a certain formational reaction to drilling by various types of drill bits. This method is also used to evaluate the effect of modifying a certain type of drill bit on drilling a certain formation (Perrin et al., 1997). Compressive strength and drilling potential were empirically correlated through experiments carried out at the early 1960 s. Although compressive strength should be described as a function of lateral stress, the fact that compressive strength is increased by lateral stress can be easily described by Mohr's failure criterion (Spar et al., 1995).

Table 1. Symbols used in the research

\begin{tabular}{|c|c|c|}
\hline Row & Symbol & Description \\
\hline 1 & $(\mathrm{D} \Delta)$ & Total time required for drilling interval \\
\hline 2 & (tb) & Total drilling time \\
\hline 3 & (tc) & Drill bit stop time \\
\hline 4 & $\mathrm{C}_{\mathrm{f}}$ & Drilling cost per unit length \\
\hline 5 & $\mathrm{C}_{\mathrm{b}}$ & Drill bit price \\
\hline 6 & $\mathrm{C}_{\mathrm{r}}$ & Operational fixed costs \\
\hline 6 & $\mathrm{~S}$ & Cohesive strength \\
\hline 7 & $\mathrm{~V}_{\mathrm{sh}}$ & Shale volume \\
\hline 8 & $\mathrm{~V}_{\mathrm{s}}$ & Shear wave velocity $(\mathrm{m} / \mathrm{s})$ \\
\hline 9 & $V_{p}$ & Compressive wave velocity $(\mathrm{m} / \mathrm{s})$ \\
\hline 10 & $\mathrm{P}$ & Density $\left(\mathrm{kg} / \mathrm{m}^{3}\right)$ \\
\hline 11 & $\mathrm{~W}$ & Weight on drill bit \\
\hline 12 & $\mathrm{~T}$ & Torque \\
\hline 13 & $\mathrm{~N}$ & Rotation speed \\
\hline 14 & A & Drill bit involved level \\
\hline 15 & $\mathrm{R}$ & Penetration rate \\
\hline 16 & $\left(\mathrm{w}_{\text {Total }}\right)$ & Total work done by drill bit \\
\hline 17 & Y & Drill bit progress \\
\hline 18 & $\mathrm{D}$ & Drill bit diameter \\
\hline 20 & AY & Volume of equal drilled rock \\
\hline 22 & FD & Drilling potential of formation \\
\hline 23 & $E=\frac{\rho V_{s}^{2}\left(3 V_{p}^{2}-4 V_{s}^{2}\right)}{V_{p}^{2}-V_{s}^{2}}$ & Young's modulus \\
\hline 24 & $G=\rho V_{s}^{2}$ & Shear modulus \\
\hline 25 & $K_{B}=\rho V_{c}^{2}-\frac{4}{3} V_{s}^{2}$ & Volumetric modulus \\
\hline 26 & $\mathrm{SE}=\mathrm{W} / \mathrm{A}+2 \pi \mathrm{NT} / \mathrm{AR}$ & Specific energy \\
\hline 27 & $C_{b}=1000 \rho_{b}\left[\frac{1}{\Delta t_{c}^{2}}-\frac{4}{3 \Delta t_{s}^{2}}\right]$ & Coutts-Deno Model \\
\hline 28 & $\mathrm{C}_{\mathrm{f}}=\left(\mathrm{C} \_\mathrm{b}+\mathrm{C} \_\mathrm{r}\left(\mathrm{t} \_\mathrm{b}+\mathrm{t} \_\mathrm{c}+\mathrm{t} \_\mathrm{t}\right)\right) / \Delta \mathrm{D}$ & Movement time of drilling string \\
\hline 29 & $\mathrm{~W}_{\text {Total }}=-\mathrm{WY}+\overline{2} \pi \mathrm{N}(\mathrm{T} / \mathrm{R}) \overline{\mathrm{Y}}$ & Work done \\
\hline 30 & $S=0.025 \times 10^{-6} \frac{E}{C_{b}}\left[\begin{array}{l}0.008 \times V_{s h} \\
+0.0045 \times\left(1-V_{s h}\right)\end{array}\right]$ & Cohesive strength based on Coutts-Deno Model \\
\hline 31 & $U C S=\frac{S}{12}$ & Uniaxial compressive strength \\
\hline 32 & $U C S=E\left[\begin{array}{l}0.008 \times V_{s h} \\
+0.0045 \times\left(1-V_{s h}\right)\end{array}\right]$ & Uniaxial compressive strength using dynamic Young's modulus and shale volume \\
\hline
\end{tabular}


Table 2. Drilled formations and their thickness

\begin{tabular}{lll}
\hline No. & Name & Thickness \\
\hline 1 & Aghajari & $1242-1360$ \\
2 & Mishan & $29-42$ \\
3 & Gachsaran & $383-516$ \\
4 & Asmari & $347-362$ \\
5 & Pabede & $261-394$ \\
6 & Gour Pei & $301-340$ \\
7 & Elam & $106.5-129$ \\
8 & Lafan & $8-37.5$ \\
9 & Sarouk & $621-705$ \\
10 & Kajdomi & $193-230$ \\
\hline
\end{tabular}

Studies performed by Warren $(1981 ; 1987)$ revealed that drilling strength can be determined for conical drill bits and used for some applications such as drilling simulation and drill bit selection. Drilling strength can be defined as resistance against drill bit penetration during drilling which is defined a function of rock characteristics.

On the other hand, some researchers have been conducted to find the relation between drilling potential, drilling penetration rate and mechanical properties of rock with electric logs as well as elastic properties of rock. Walker et al. (1986) suggested some equations which correlated the weight on drill bit, depth, in-place compressive strength, porosity and average size of rock grains to penetration rate of conical drill bits. However, in-place compressive strength used in their relations required to use information such as weight on bit and the angle of internal friction which is obtained from drilling information as well as mechanical rock tests.

Some researchers have tried to present a nondimensional parameter by combining these influential factors and some others have presented these factors relatively through introducing a base. These factors have been presented as drilling potential, design index, drilling index and so on.

\section{Resistance against Drilling}

As stated earlier, there are limited and unproved methods to determine the resistance factors of formation. However, in oil drilling, resistance against drilling is more important than absolute resistance of rock. In most of researches, some relations have been proposed to determine factors such as compressive uniaxial strength using well data. However, the results obtained from these relations are in fact resistant against drilling in spite of the fact that they have been introduced as uniaxial compressive strength. This issue has been well shown in current investigation in the considered field. To this end, two methods have been used to determine drilling resistance from $\log$ well data. One of the methods of determining drilling resistance is based on Cots-Deno model. In this method, firstly, volumetric compressibility is calculated using traveling time of the compressive and shear wave as well as density equation (Al-Qahtani and Zillur, 2001).

Then, cohesive strength is calculated based on Coutts-Deno model, using Young modulus, volumetric compressibility and shale size. Finally, uniaxial compressive strength which is the compressive stress required for fracturing nonenclosed rock species is obtained.

Another method which is used in this study is determining drilling resistance using Young modulus and shale volume. In this popular method, uniaxial compressive strength is obtained from Equation 11, using dynamic Young modulus as well as shale volume Gavito (1996). Table 1 and 2 summarize symbols used in this study and characteristics of the formation employed in the research.

\section{Results}

In present paper, drillings with short-drill bit, which have been ended due to some reasons other than inappropriate drill bit performance, were eliminated and length unit drilling cost was then calculated. Time of reciprocation and replacement of drill bit was theoretically calculated and by considering one hour per $1000 \mathrm{ft}$ to remove measurement errors as well as preventing entrance of factors irrelevant to drill bit performance which exist in recorded times in daily drilling report. The price of drill bits was also extracted from the reports of purchasing drill bit for the first three wells related to their purchasing year. Based on the cost of the rig (20000 dollars per day), the rig cost (900 dollars per hour) was obtained. The type of drill bits and the onset and end of the drilling were calculated from tables of records of drill bits used for various wells. Accordingly, length unit drilling cost was calculated. After calculating length unit drilling cost, drill bits used for each well were separately evaluated.

The considerable point about drilling well 3 is the use of drill bits with the same code, different formations and length unit drilling cost (Fig. 1). Two groups of drill bits which are more extensively used are drill bits 437 and 537. Drill bits 437 drilled in the first and third formations and in the second formation which have dolomite rocks with limerock inter-layers and little amounts of anhydrite layers in some depths have yielded the highest length unit drilling cost (511.9 dollars per meter). Drill bits 537 have yielded the maximum length unit drilling cost (219 dollars per meter) in the first formation. In well no. 3 which has the maximum length unit drilling cost like other wells, the last well has had the highest cost (Fig. 2). One reason is the depth of the formation $(3044 \mathrm{~m})$ and consequently, the increase of length unit drilling cost leads to the increase of depth. 


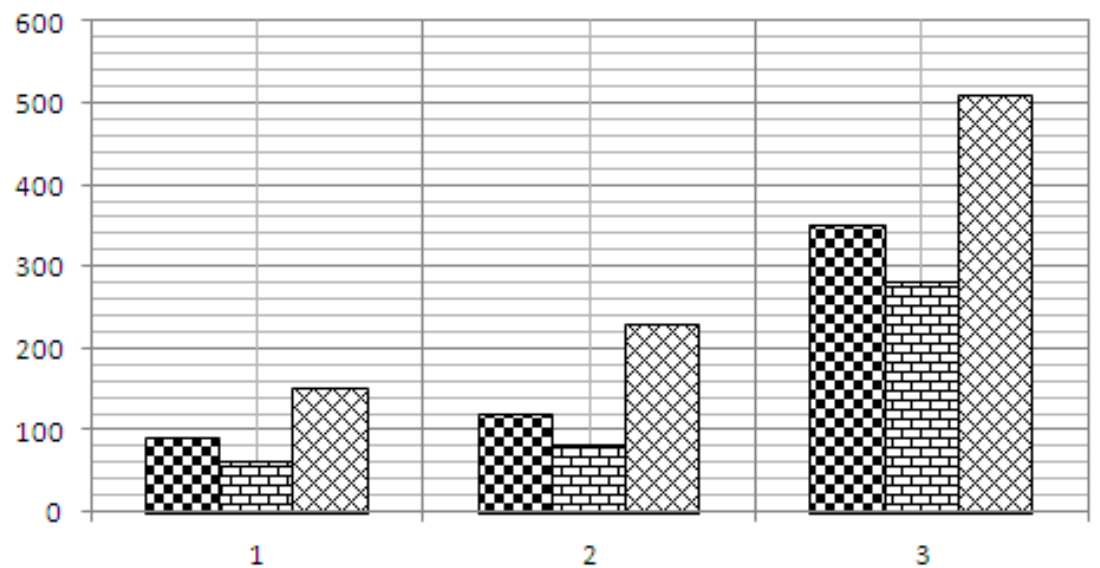

Fig. 1. Drilling cost (cost/m USD) length unit drilling cost for drill bits used in three wells

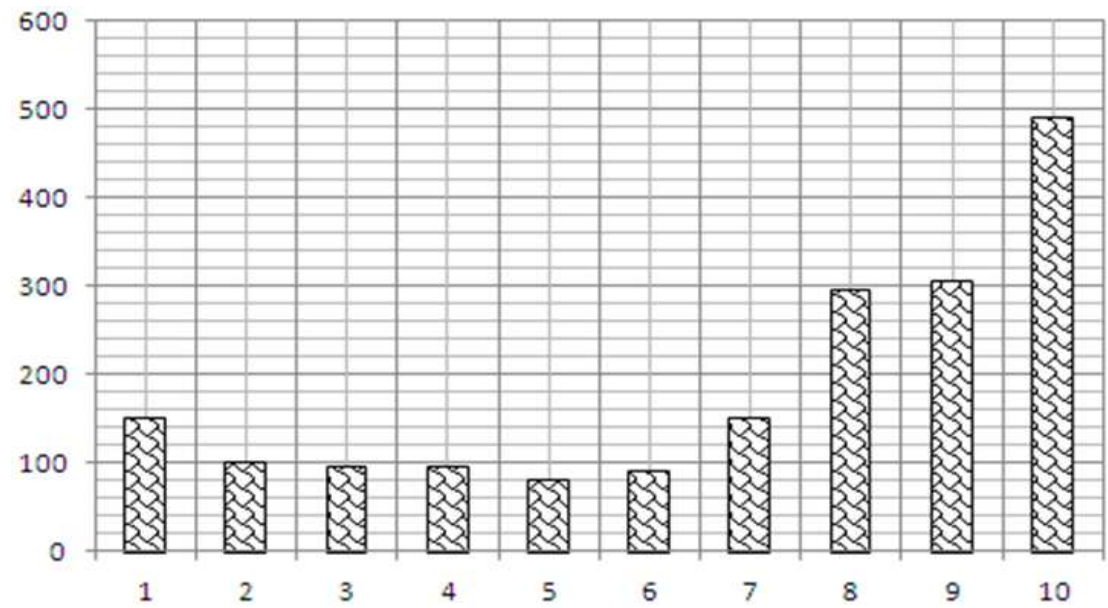

Fig. 2. The average drilling costs of the drilled formation

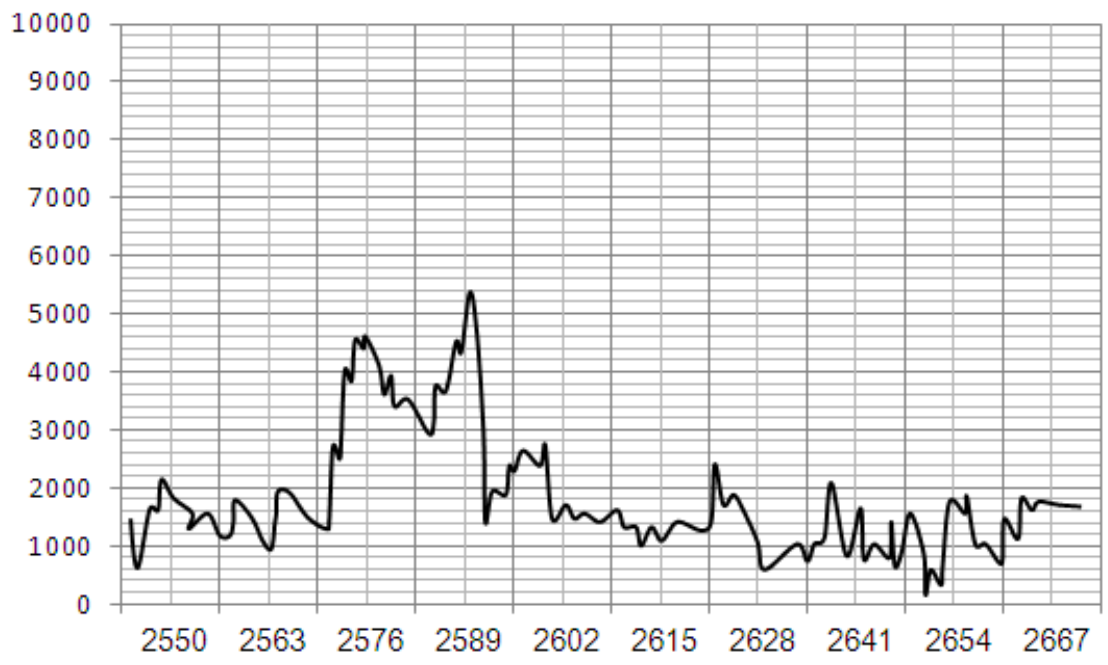

Fig. 3. Specific energy (MPa) versus depth 


\section{SE Calculation in the Studied Wells}

In present work, drilling SE in which penetration rate and instantaneous torque are measured illustrates that SE method is strongly depends on geological and geo-mechanical properties changes of formation. The dependence of the SE upon lithological changes is measured in SE diagrams in the depth 17 times of the drill bit length in which penetration rate and torque are measured. Calculations illustrate the strong dependence of the SE upon geological and geomechanical changes in the formation. For instance, the dependence of SE on lithological changes in SE diagram against the depth of drill bit 17 has been shown in Fig. 3, revealing the increase of SE due to the increase of shale volume. As observed, the increase of shale volume leads to the increase of SE. Therefore, geological changes should be also considered during evaluating drill bit using SE method. They have to be considered since sudden changes in geological and geo-mechanical properties during drilling in a layer with lower penetration rate leads to a sudden increase in SE and the layer returns to its previous level after passing through it. Therefore, by considering these changes, early replacement of drill bit is prevented (Fig. 4).

Another main challenge in evaluating the efficiency of drill bit using SE method is high sensitivity of this method to drilling operational factors. This sensitivity leads to considerable changes in SE in a finite interval so that in some cases, it is not possible to evaluate drill bit with this method.

In exploring drilling potential, the first step is to estimate geo-mechanical factors of the formation. In this study, these factors are classified into two groups: dynamical elastic modules of rock (Young, shear and volumetric modules) and resistive factors of formation. The reason for this classification is that in dynamic modules, there are fixed and globally accepted relations thereby and using traveling time of the compressive and shear waves as well as the density of rock, such modules can be calculated. However, to evaluate the resistive parameters of rock using information available about formations, there is no unified and globally accepted method in oil industry but the available methods are hypothetical and their effectiveness has been proved only in limited cases.

To determine dynamic elastic modules of rock, in addition to the traveling time of the compressive wave, shear wave is required as well. However, in the studied field, just like most of the oil and gas fields of Iran, traveling time of the shear wave has not been measured. Hence, traveling time of the shear wave must be estimated using that of compressive wave. Traveling time of the shear wave was calculated by obtaining representative porosity, density, traveling time of compressive wave of the available rocks as well as results obtained from studies on the three other oil fields of Iran for the ratio of the shear to compressive waves traveling time (Azizi and Memarian, 2006). For anhydrite, calcite, dolomite and illite, it was calculated $1.85,1.9,1.75$ and 1.84 , respectively. The summary of these calculations has been represented in Fig. 5-7. After calculating shearing wave's traveling time, Young, shear and volumetric modulus for different formations and intervals drilled by different drill bits were calculated.

After calculating shear wave's traveling time, Young modulus (E), shear modulus (G) and volumetric modulus (K) are calculated (Teale, 1965; Khuleif and Al-Naser, 2005).

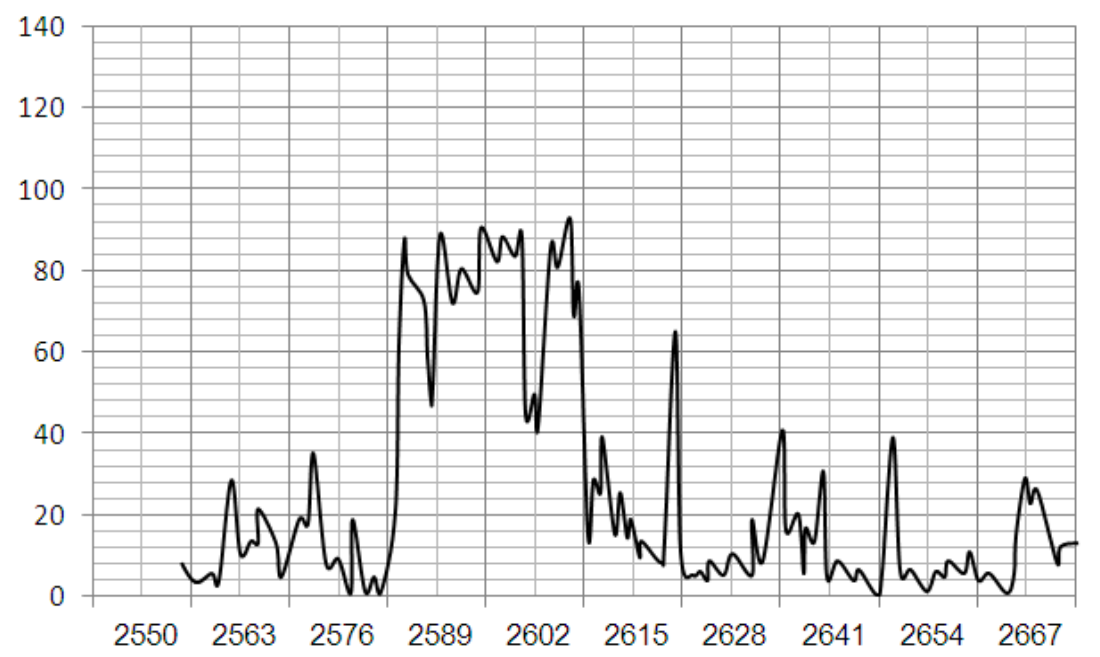

Fig. 4. Shale percentage versus depth 


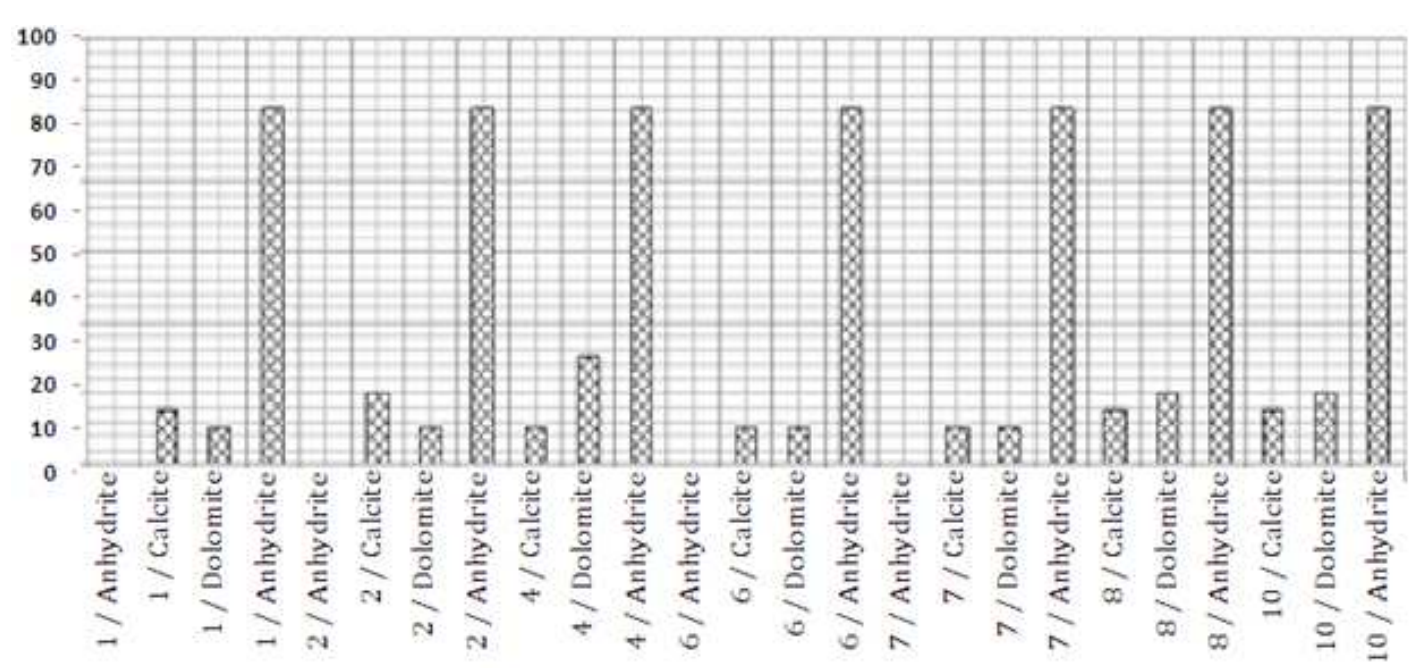

Fig. 5. Porosity (\%) of the studied rocks

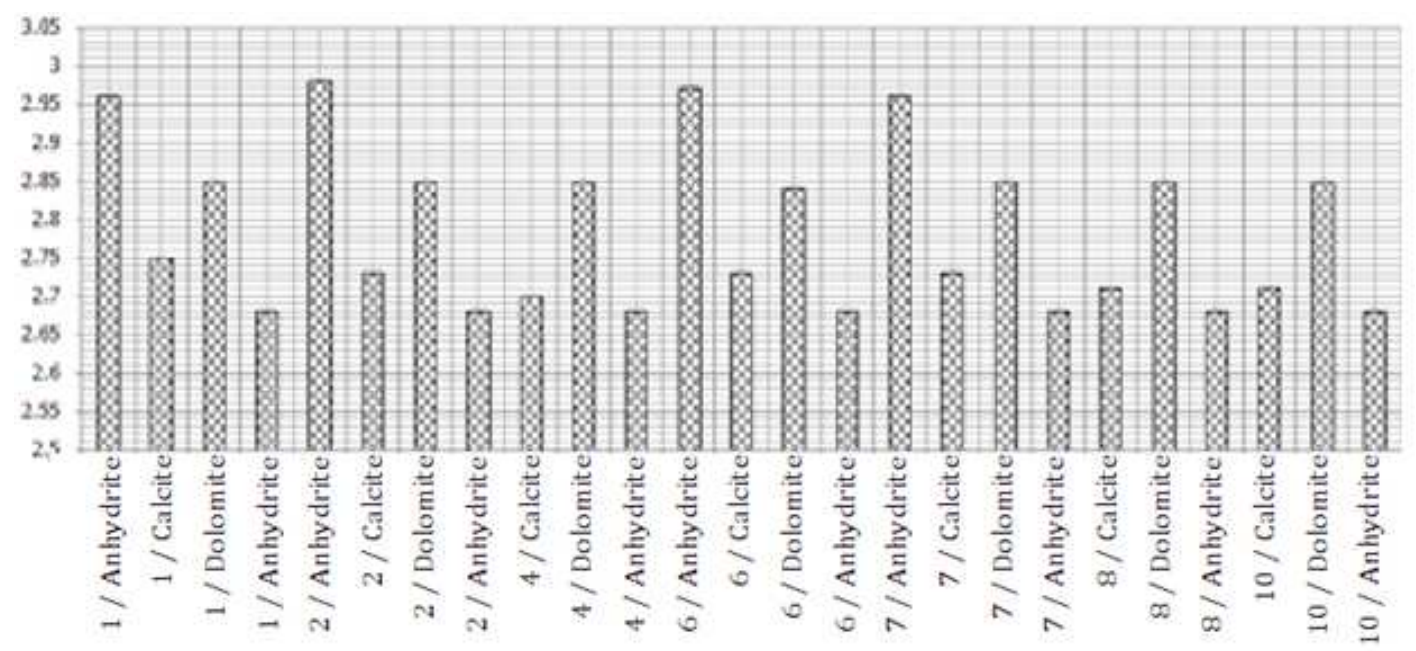

Fig. 6. Density $\left(\mathrm{kg} / \mathrm{m}^{3}\right)$ of the studied rocks

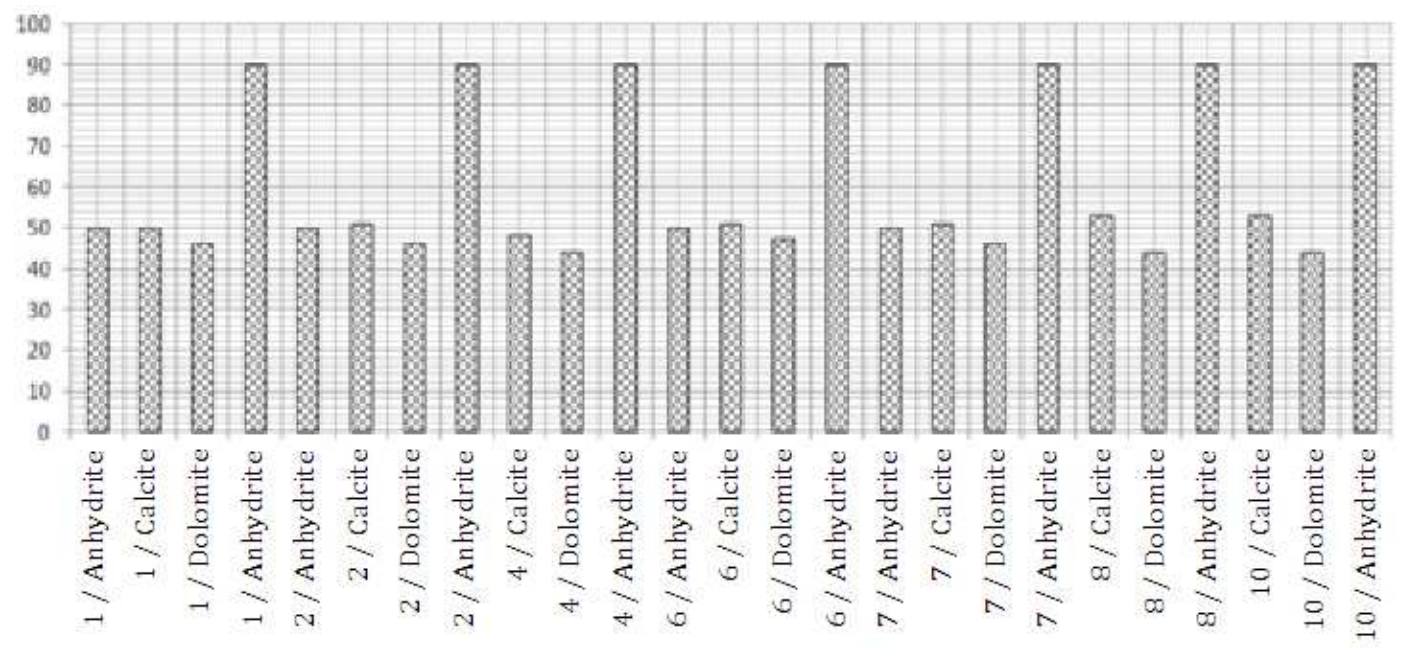

Fig. 7. Traveling time of the studied rocks 


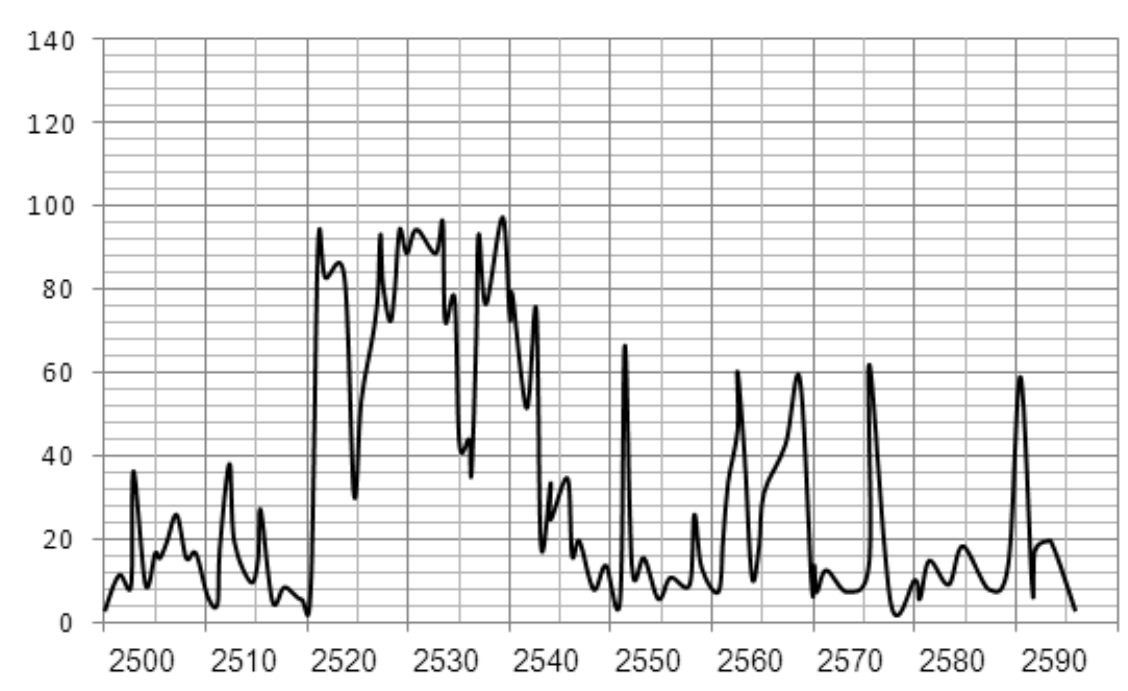

Fig. 8. Shale percentage in the depths of 2500-2600 m

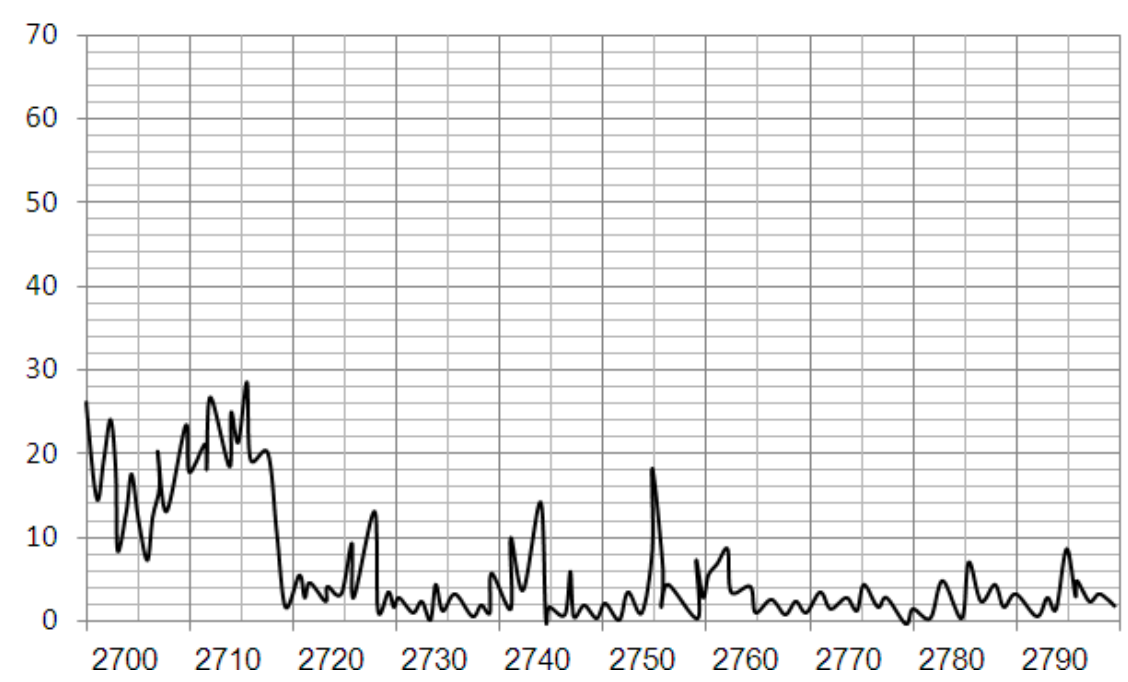

Fig. 9. Shale percentage in the depths of 2700-2800 m

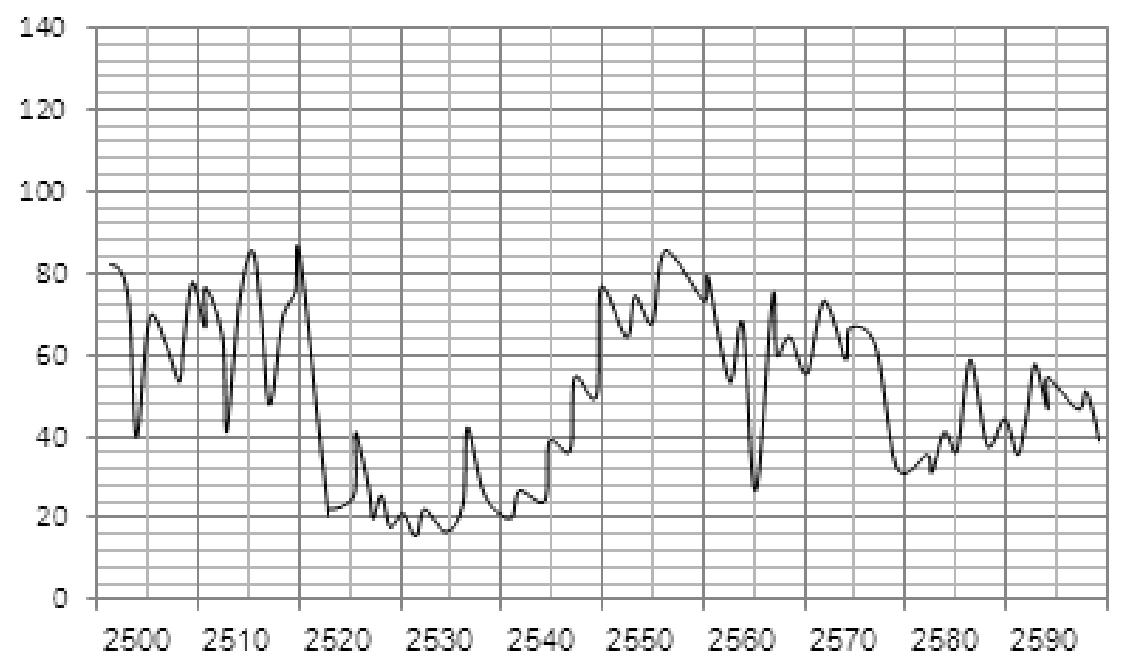

Fig. 10. E (GPa) in the depths $2500-2600 \mathrm{~m}$ 


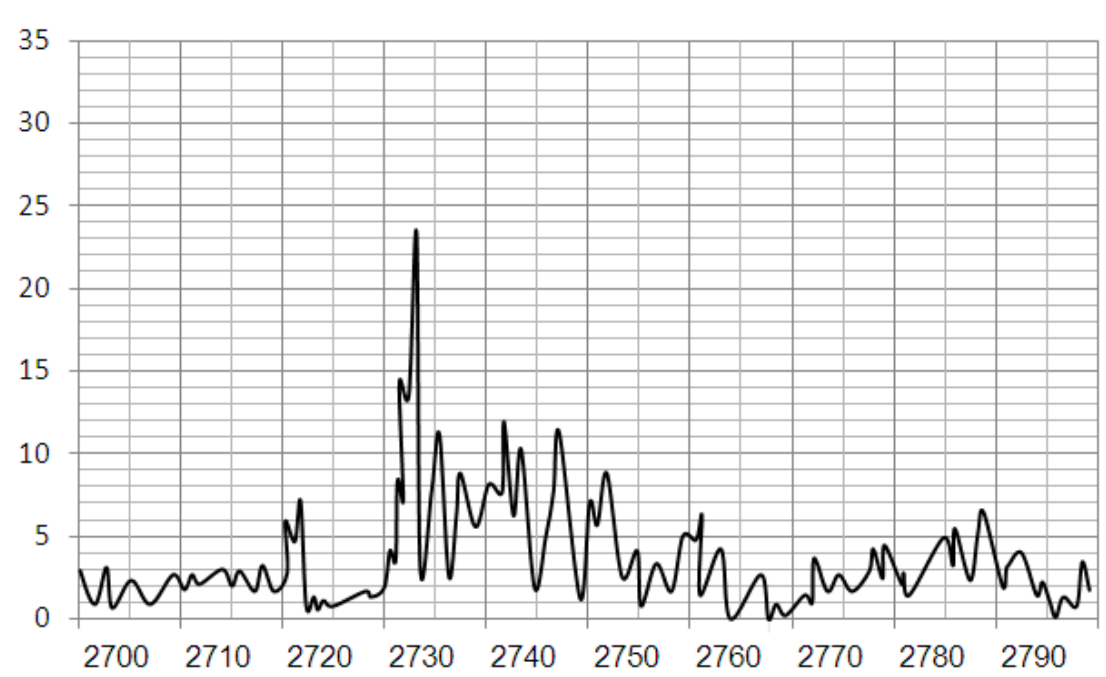

Fig. 11. Porosity (\%) in the depths of 2700-2800 m

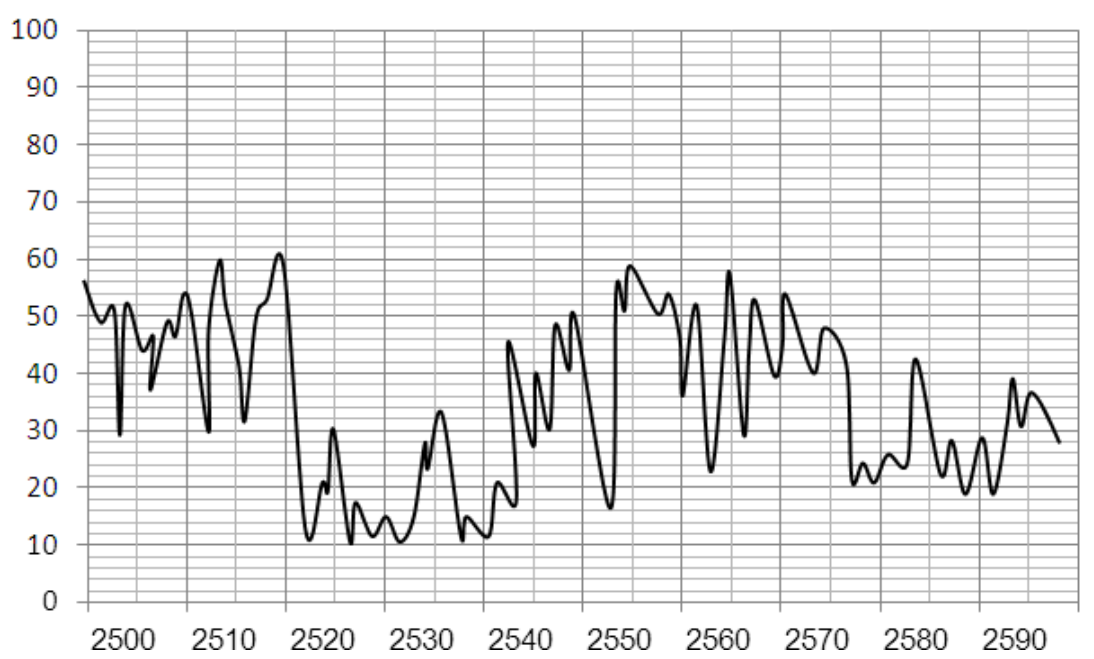

Fig. 12. G (GPa) for 2500-2600m depth

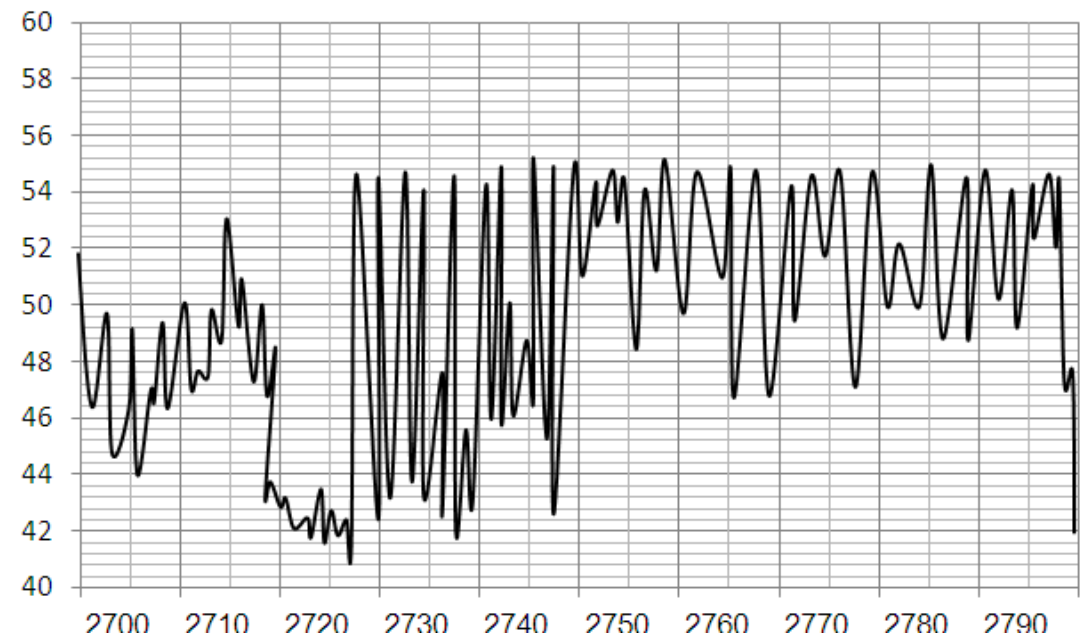

Fig. 13. DS.1 (MPa) in the depth of $2700-2800 \mathrm{~m}$ 


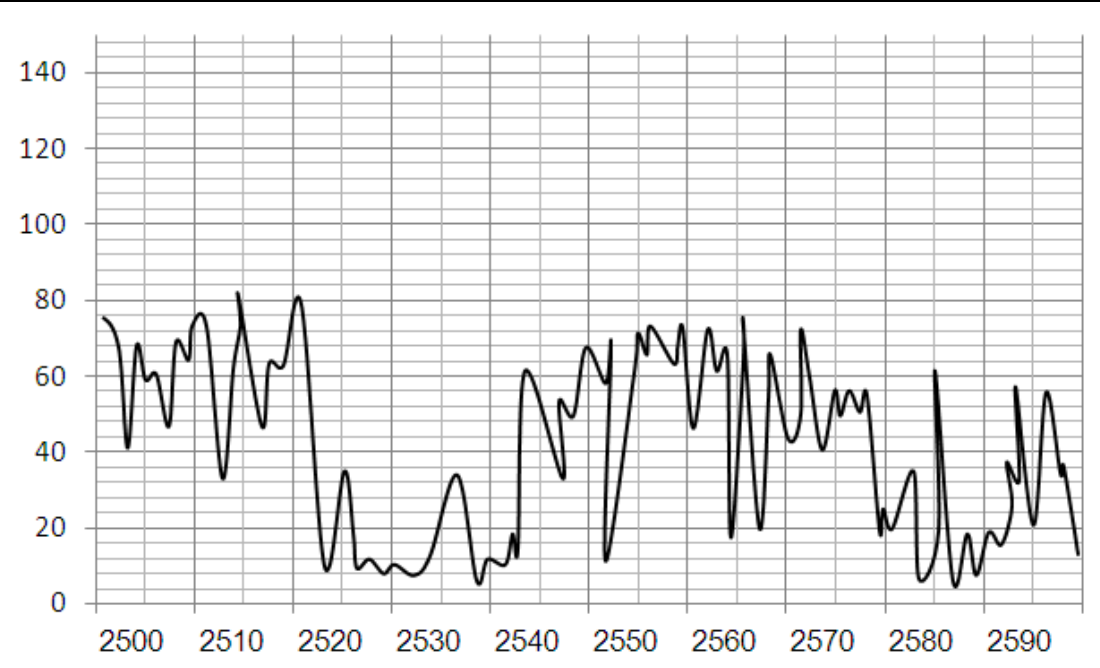

Fig. 14. K (GPa) in the depth of $2500-2600 \mathrm{~m}$

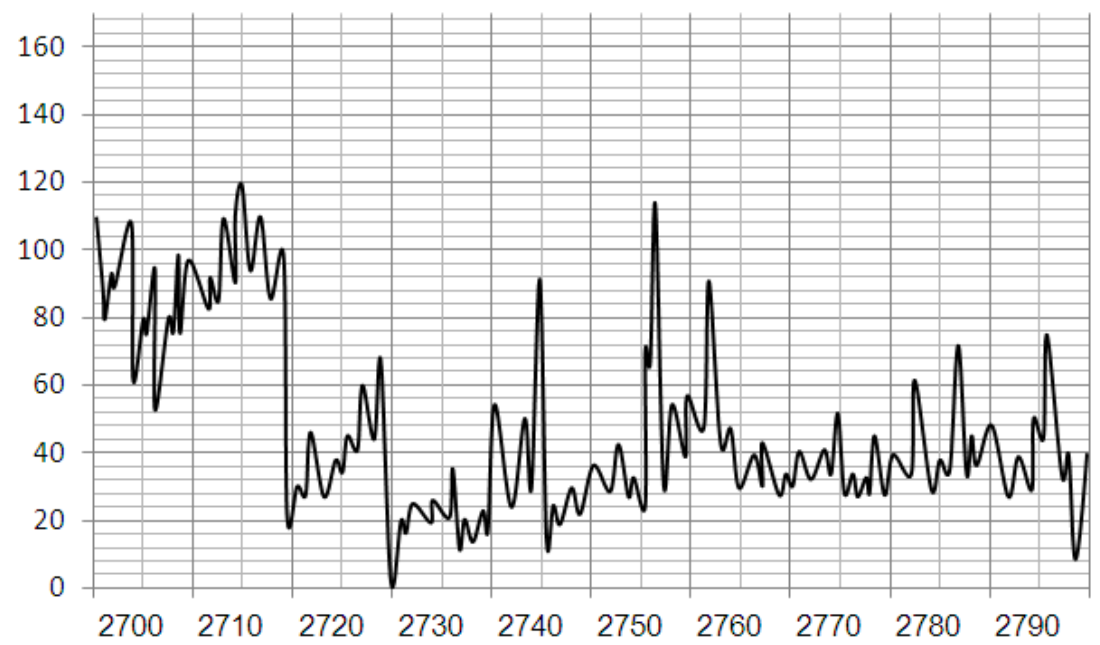

Fig. 15. DS.2 (MPa) in the depths of $2700-2800 \mathrm{~m}$

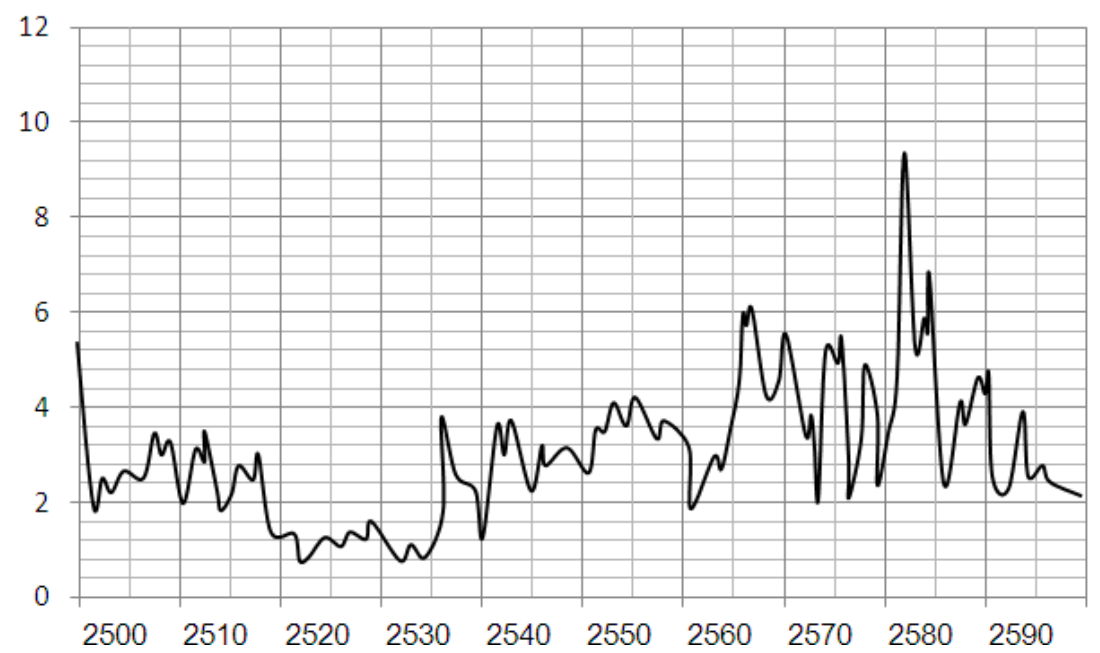

Fig. 16. ROP (m/hr) in the depth of $2700-2800 \mathrm{~m}$ 


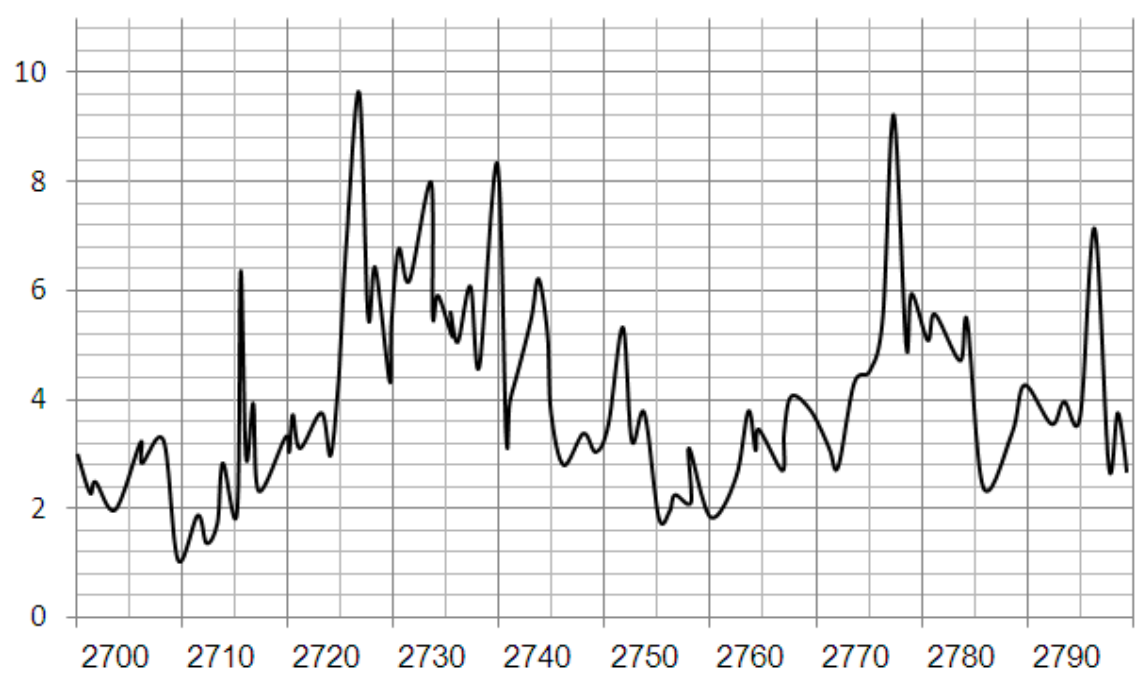

Fig. 17. SE (MPa) in the depth of $2700-2800 \mathrm{~m}$

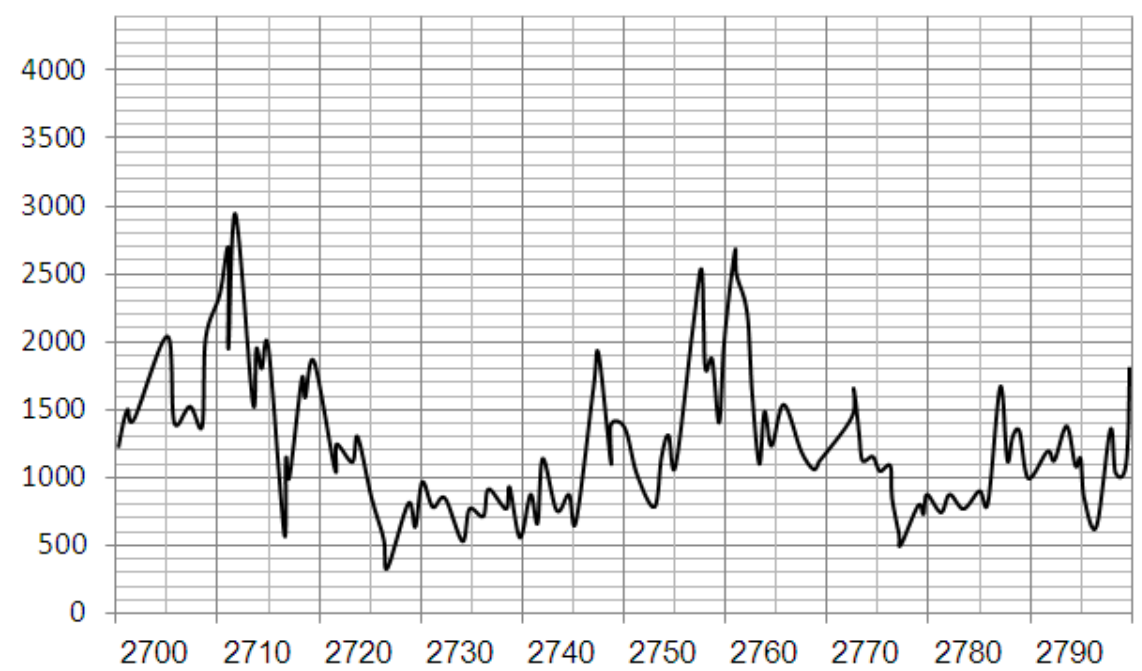

Fig. 18. S.E (MPa) in the depths $2700-2800 \mathrm{~m}$

\section{Geo-Mechanical Factors}

Previously conducted studied in this field have focused on five drill bits with the information necessary for determining the modules, strength as well as penetration rate. Formations rocks drilled by these drill bits including calcite, dolomite and shale were identified as rock contributing to the penetration rate by investigating penetration rate of various rocks in this field. Therefore, in exploring diagrams of dynamic modules of rock versus penetration rate, diagram of shale percentage was evaluated as well.

In intervals with shale, even with relatively low elastic modulus of rock, penetration rate is low. Diagram of shale percentage, elastic modules and penetration rate of drill bit in two different depths have been shown in Fig. 8-18. As shown in diagrams, in the depth of 2500-2600 m, as shale percentage is increased, the value of dynamic elastic modules of rock is decreased. This matter can be justified with respect to the increase in porosity in intervals with shale as well as low resistance of the shale to other rocks available in this field. Due to the direct relation between rock strength and elastic modules, it is expected that in intervals with shale, penetration rate is increased owing to the relatively low value of elastic modules. However, contrary to the expectations, in these intervals, penetration rate not only is not increased, but also it is even lower compared to other intervals. The reason of this phenomenon is high cohesion of shale and consequently the adhesion of drilled particles into drill bit and its penetration reduction. 
As the studies on this field revel, in intervals with high shale content, elastic modules are decreased while due to drilling problems in shales, penetration rate is also decreased. However, in intervals without shale, as elastic modules and accordingly, rock strength are decreased, penetration rate is increased. It must be pointed out that low quantities of shale can contribute to penetration rate. This fact has been reflected in relations presented to estimate drilling resistance using data of well logs. While the increase in shale amount, with respect to other rocks existing in this field and relatively high porosity, is accompanied with uniaxial compressive strength reduction, resistance obtained from these relations is increased by the increase of shale percentage. This issue reveals the fact that strength given by these relations is drilling resistance but not uniaxial compressive strength.

The considerable point in this diagram is the reduction of drilling resistance as a result of the increase in porosity in intervals without shale in the depth of 2700-2800 m. At the same time, SE reduction due to drilling strength reduction is of high importance in these intervals which well illustrates the ability of the calculated drilling resistance to estimate actual drilling conditions. In this drill bit diagram, the calculated drilling resistance has many changes and sometime on-correlated changes with geological and geo-mechanical conditions as well as drilling operational factors. This implies the failure of this method to estimate drilling conditions and select the appropriate right drill bit.
To evaluate the calculated geo-mechanical factors, the average of elastic modules and the resistance obtained from aforesaid methods for drill bits investigated in the well have been compared with the results of penetration rate, SE as well as drilling length unit drilling cost. The results have been presented in Fig. 19-23. Drill bit 21 and 11 both have drilled in two wells with the same geological properties. In terms of geo-mechanical properties, the measured parameters indicate the similarity of the geo-mechanical properties of the drilled formation by these drill bits. However, drill bit 11 has higher penetration rate and SE as well as considerable lower length unit drilling cost. Therefore, considering all of the aspects, it can be said that in general, drill bit driven in the first well is better than the one driven in the second well. Consequently, drill bit 437 driven in first well is better compared to the drill bit 547 driven in second well.

The obtained results of this method require investigating drilling operational factors. Operational factors must be involved to determine drilling potential. This potential is obtained by combining the parameters determined in this research as well as many other factors. For instance, drill bit 18 of the first well and drill bit 8 of the second well both have drilled Kangan formation with the same geological and geo-mechanical properties. Despite of this similarities and while both drill bits are of the same code (527) and made by the same company, their penetration rate, SE and length unit drilling cost are considerably different. It highlights the effect of the operational factors on the efficiency of the drill bits.

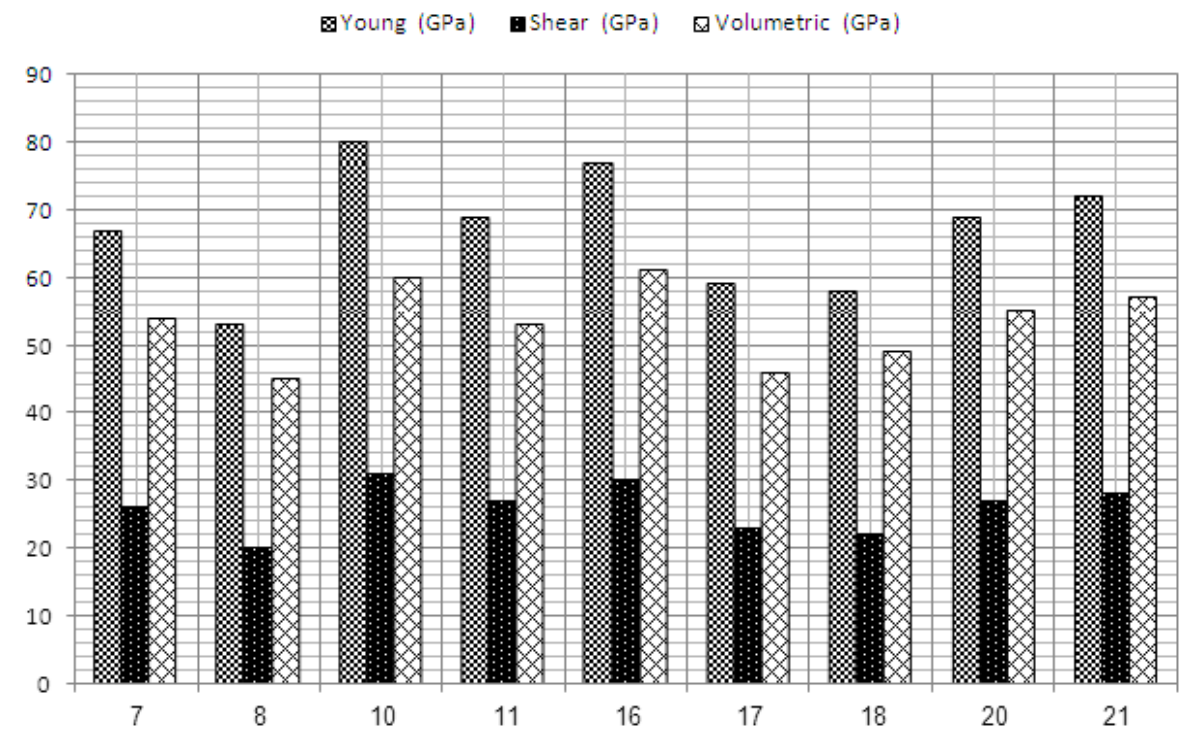

Fig. 19. The average elastic modules of the studied drill bits 


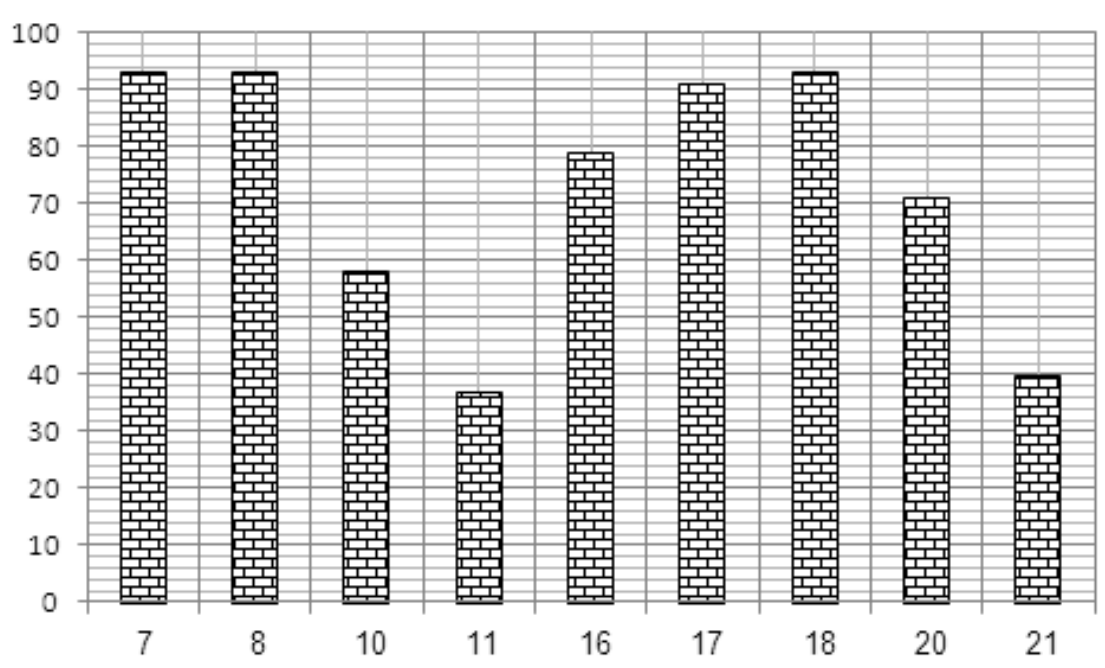

Fig. 20. DS2 (MPa) for drill bits

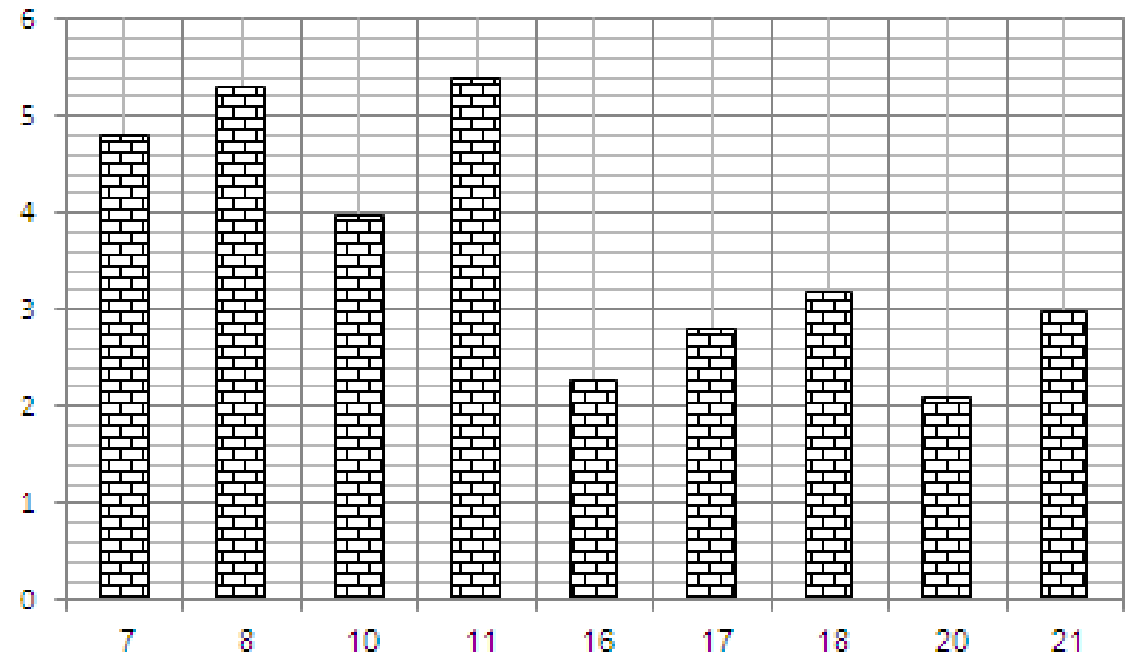

Fig. 21. The average penetration rate of drill bits $(\mathrm{m} / \mathrm{hr})$

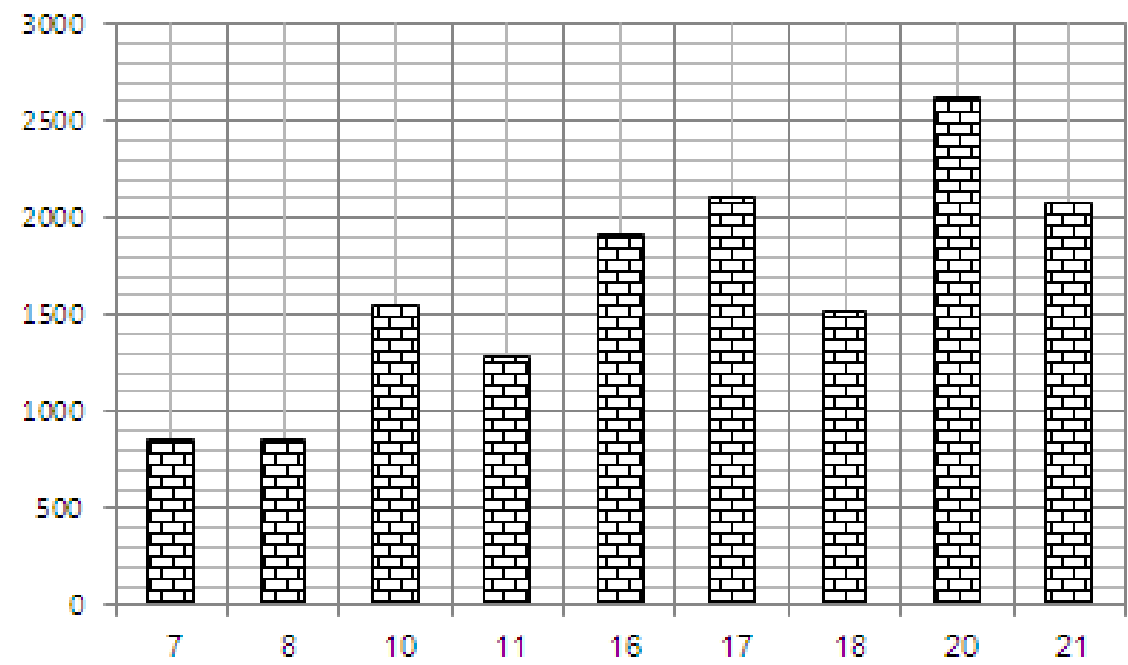

Fig. 22. The average SE (MPa) of drill bits 


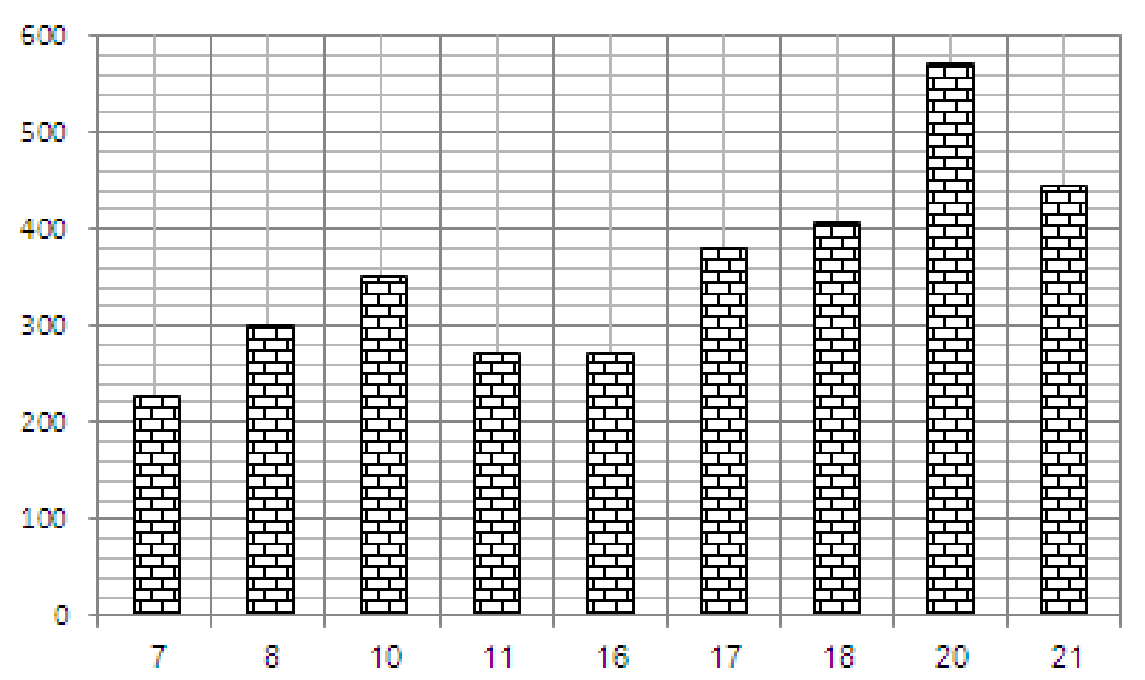

Fig. 23. Cost per unit length (USD)

\section{Conclusion}

In this study, length unit drilling cost of various formations drilled in 10 wells was evaluated. Comparison and evaluating the length unit drilling cost of various wells formations, optimal drill bit, i.e., the drill bit drilling with the least cost was introduced.

There are two methods to evaluate the performance of drill bits based on length unit drilling cost: Comparing drill bits with the same code and comparing the performance of drill bits used in the same formation in different wells and finally, the optimal drill bit selection. In studies performed on different wells, it was concluded that drill bits with the same code have different length unit drilling cost in various formations. This difference sometimes reaches to several times more than length unit drilling cost. Therefore, it can be concluded that geological and geo-mechanical factors which are often ignored in evaluating drill bit performance, have a significant effect on drilling performance. To sum up, it can be said that the maximum efficiency of drill bit selection based on length unit drilling cost is the optimal drill bit selection which present the least drilling cost in a formation with certain geological and geo-mechanical properties.

Briefly, it can be stated that SE fails to be used as an ideal complement for length unit drilling cost method. It is due to the fact that it depends on parameters irrelevant to the performance of drill bit, abundant changes in an interval with relatively stable geological and geo-mechanical properties as well as the need of measuring torque throughout the well.

According to many empirical models of determining uniaxial compressive strength and assuming constant conditions, the increase of porosity leads to the decrease of uniaxial compressive strength. Thus, in evaluations of uniaxial compressive strength, porosity and SE diagram were considered as well. However, in these diagrams, the increase of porosity, which represents the increase of level of shale content, uniaxial compressive strength is also increased, based on the above calculations. This fact is in contradiction with geo-mechanical principles and empirical relations of determining uniaxial compressive strength. This issue emphasizes on the fact that the presented relations are used to determine drilling resistance but not uniaxial compressive strength.

As shown in the figure, the increase of shale percentage leads to the increase of porosity. By increasing the calculated resistances, it is highlighted that measured resistances are resistance against drilling and are not against uniaxial compressive strength. As drilling resistance is increased in these depths, penetration rate is decreased and SE spent for drilling the rocks of this interval is increased. Given that the increases in the calculated drilled resistances is accompanied with the decrease in penetration rate and the increase in SE. Moreover, since they directly evaluate the geological and geo-mechanical properties of the formation, the calculated resistances can be used as an ideal complement for length unit drilling cost to evaluate the consumed drill bits and select next ones.

In summary, it can be said that some of the relations to determine compressive strength of rock from well log data for oil and gas wells can calculate resistance against drilling. Among these relations, two relations which can be used with the data of the studied field were evaluated. Coutts-Deno Model cannot be a useful method for drill bit selection due to wide changes in a short range with relatively stable geological and geo-mechanical conditions as well as the lack of correlation with penetration rate and SE. 
On the other hand, Equation 33 has a great potential to evaluate resistance against drilling. High correlation of resistance calculated by Equation 33 with penetration rate and SE indicates the ability of the method in modeling actual conditions of well drilling. Consequently, based on the conducted studies on this field, Equation 33 can be used as an ideal complement along with length unit drilling cost for appropriate drill bit selection. Moreover, drilling operational factors which contribute to the performance of drill bit must be taken into consideration.

Investigating performance of drill bits used in six wells of a gas field in south of Iran led to the following conclusions:

- Length unit drilling cost cannot be used separately to evaluate drill bits employed in drilling and select new ones because it lacks a valid and fixed basis to compare rocks with different geological and geomechanical characteristics

- In length unit drilling cost, if there are extensive changes in geological and geo-mechanical properties of the same formation, it is not possible to compare drill bits used in that formation and propose the optimal drill bit

- For various reasons such as dependence on irrelevant factors including the need of measuring torque throughout the well (which does not usually occur) and considerable changes in a limited interval, SE method cannot be an ideal complement for length unit drilling cost

- Some of the relations given to determine compressive strength of rock from well log data, indeed, calculate resistance against drilling and applying them as uniaxial compressive strength is accompanied with high approximation

- Based on the conducted studies, the method of determining drilling resistance based on CouttsDeno Model cannot be a useful method for drill bit selection due to wide changes in a short range with relatively stable geological and geo-mechanical conditions as well as the lack of correlation with penetration rate and $\mathrm{SE}$

- Determining drilling resistance using Young's modulus and shale volume has a great potential to determine resistance against drilling. High correlation of the resistance calculated using this method with penetration rate and SE reveals the capability of the method for modeling actual conditions of the well drilling. Therefore, according to the conducted studies, this method can be used as an ideal complement for appropriate drill bit selection along with drilling cost per unit length. Of course, the results of this method must be moderated based on drilling operational factors

\section{Acknowledgement}

I would like to express my special thanks of gratitude to my teacher Prof. Maria João Pereira as well as our principal Prof. Amílcar Soares who gave me the golden opportunity to do this wonderful project, which also helped me in doing a lot of Research and I came to know about so many new things I am really thankful to them. Secondly I would also like to thank my parents and friends who helped me a lot in finalizing this project within the limited time frame.

\section{Ethics}

This article is original and contains unpublished material. The corresponding author confirms that all of the other authors have read and approved the manuscript and that there are no ethical issues.

\section{References}

Adams, N.J. and T. Charrier, 1985. Drilling Engineering: A Complete Well Planning Approach. 1st Edn., PennWell Pub. Co., Tulsa, ISBN-10: 0878142657, pp: 960.

Al-Qahtani, M. and R. Zillur, 2001. A mathematical algorithm for modeling geomechanical rock properties of the khuff and pre-khuff reservoirs in ghawar field. Proceedings of the SPE Middle East Oil Show, Mar. 17-20, SPE, Manama, Bahrain. DOI: $10.2118 / 68194-\mathrm{MS}$

Azizi, V. and H. Memarian, 2006. S wave velocity estimation for evaluating geomechanical properties of rocks in oil and gas wells of Iran. Proceedings of the 1st Iranian Petroleum Engineering Congress, May 30-31, Tehran.

Bourgoyne, Jr. A.T., K.K. Millheim, M.E. Chenevert and F.S. Young Jr, 1991. Applied Drilling Engineering. 1st Edn., SPE, USA.

Farrelly, M. and H. Rabia, 1987. Bit performance and selection: A novel approach. Proceedings of the SPE/IADC Drilling Conference, Mar. 15-18, SPE, New Orleans, Louisiana. DOI: 10.2118/16163-MS

Gavito, D.G., 1996. A new rock strength model and its practical applications. Proceedings of the International Petroleum Conference and Exhibition of Mexico, Mar. 5-7, SPE, Villahermosa, Mexico. DOI: $10.2118 / 35322-M S$

Jansen, J.D., 1990. Non-linear rotor dynamics as applied to oil well drill string vibrations. J. Sound Vibrat., 147: 115-135. DOI: 10.1016/0022-460x(91)90687-F

Jasen, J.D. and L. Van Den Steen, 1993. Active damping of self excited torsional vibrations in oil well drill strings. J. Sound Vibrat., 179: 647-668.

DOI: $10.1006 /$ jsvi.1995.0042 
Khuleif, Y.A. and H. Al-naser, 2005. Finite element dynamic analysis of drill strings. Finite Element Anal. Design, 41: 1270-1288.

DOI: 10.1016/j.finel.2005.02.003

Paidoussis, M.P. and N.T. Issid, 1973. Dynamic stability of pipes conveying fluid. J. Sound Vibrat., 33: 267-294. DOI: 10.1016/S0022-460X(74)80002-7

Paidoussis, M.P., 1966. Dynamics of flexible slender cylinders in axial flow. Part 1. Exp. J. Fluid Mechan., 26: 736-753.

DOI: $10.1017 / \mathrm{S} 0022112066001484$

Perrin, V.P., G. Mensa-Wilmot and W.L. Alexander, 1997. Drilling index-a new approach to bit performance evaluation. Proceedings of the SPE/IADC Drilling Conference, Mar. 4-6, SPE, Amsterdam, Netherlands. DOI: 10.2118/37595-MS

Rabia, H., 1985. Oilwell Drilling Engineering. 1st Edn., Graham and Trotman, London, ISBN-10: 0860107140, pp: 322.

Rabia, H., M. Farrelly and M.V. Barr, 1986. A new approach to drill bit selection. Proceedings of the European Petroleum Conference, Oct. 20-22, SPE, London. DOI: 10.2118/15894-MS

Spar, J.R., L.W. Ledgerwood, H. Goodman, R.L. Graff and T.J. Moo, 1995. Formation compressive strength estimates for predicting drillability and PDC bit selection. Proceedings of the SPE/IADC Drilling Conference, Feb. 28-Mar. 2, SPE, Amsterdam, Netherlands. DOI: 10.2118/29397-MS
Teale, R., 1965. The concept of specific energy in drilling. Int. J. Rock Mech. Min. Sci., 2: 57-73. DOI: 10.1016/0148-9062(65)90022-7

Thomas, J.M., 1989. Case history: PC analysis of bit records enhances drilling operations in southern Alabama. SPE Comput. Applic., 2: 14-17. DOI: $10.2118 / 18632-P A$

Walker, B.H., A.D. Black, T.L. Klanker and M. Khodavierdian, 1986. Roller bit penetrating rate response as a function of rock properties and well depth. SPE.

Warren, T.M., 1981. Drilling model for soft-formation bits. JPT, 33: 963-970. DOI: 10.2118/8438-PA

Warren, T.M., 1987. Penetration rate performance of roller cone bits. SPE Drill. Eng., 2: 9-18. DOI: $10.2118 / 13259-P A$

Yigit, A.S. and A.P. Christoforou, 1997. Dynamic modeling of rotating drill strings with borehole interactions. J. Sound Vibrat., 206: 243-260. DOI: $10.1006 /$ jsvi.1997.1091

Yigit, S. and A.P. Christoforou, 1996. Coupled axial and transverse vibration of oil well drill string. J. Sound Vibrat., 195: 617-627. DOI: 10.1006/jsvi.1996.0450 